\title{
La organización del conocimiento desde la perspectiva poscolonial: itinerarios de la paraconsistencia
}

\section{Antonio García Gutiérrez}

\author{
Catedrático de Universidad Universidad de \\ Sevilla. España
}

Los procesos de producción, transmisión y organización del conocimiento son interferidos, como el resto de las prácticas simbólicas, por acciones colonizantes culturales y cognitivas desde los inicios de su sistematización. La desclasificación propone la rehabilitación de viejos valores desterrados por el pensamiento hegemónico como la estesia, la incertidumbre, la provisionalidad, la retórica o la contradicción con el fin de obtener una organización del conocimiento emancipante y autonarrativa quebrando los límites de la matriz cognitiva que sustenta el proyecto epistémico occidental, ahora exponencialmente impulsado por la digitalidad. En este artículo se aborda, especificamente desde una perspectiva paraconsistente, el estatuto imposible de los conceptos cerrados y sus jerarquías y se establecen tres postulados teóricos de trabajo para quebrar y abrir sus límites.

Palabras clave: Organización del conocimiento; Descolonización; Desclasificación; Paraconsistencia; Digitalidad.

\section{Knowledge organization from a postcolonial perspective: paraconsistency routes}

The processus of production, transmission and organization of knowledge are interfered, as other symbolic practices, by colonizing cultural and cognitive actions since the beginning of its systematization. "Declassification" proposes the rehabilitation of old values, banished by hegemonic thinking, such as aesthesia, uncertainty, temporarity, rhetoric or contradiction in order to obtain a self-narrative and emancipation-oriented knowledge organization, breaking 
the bounds of the cognitive matrix which is behind the western epistemic project, now exponentially launched by digitality. In this article the impossible closed concepts statute and its hierarchies are specifically addressed from a paraconsistent perspective, and three principles of work are theoretically set in order to break and open their limits.

Keywords: Knowledge organization; Decolonization; Declassification; Paraconsistency; Digitality.

Recebido em 18.03.2013 Aceito em 17.09.2013

\section{Introducción}

Cuando hablamos de conocimiento, solemos invocar indicadores incuestionables como consistencia, coherencia, consenso, racionalidad, centralidad, impacto, visibilidad, expansión, unidad, normalidad, organización, orden, jerarquía, por no mencionar otros de tintes más mercantiles ${ }^{1}$. En este texto, sin embargo, abordaremos el conocimiento desde lugares menos complacientes, lugares de destierro -0 de soterramiento- instaurados ya en los albores de su sistematización: contradicción, incertidumbre, ambigüedad, provisionalidad, pulsión, debilidad, subalternidad, disenso, aleatoriedad, categorías en las que ha hallado refugio la estesia. La estesia, debemos recordar con Muniz Sodré (2002), se ocupa del estudio de lo sensible, eclipsada desde muy antiguo por la estética, al centrar el foco en lo bello, y por la ética al ocuparse de lo bueno. El olvido, o el descuido, de la estesia ha sido tal en nuestra cultura que, de hecho, apenas la nombramos si no es desde su radical antonimia: la anestesia. Lo mismo ocurre con otros conceptos, asociados a la estesia, como la pasibilidad, la capacidad de sorprenderse, invisibilizada por su opuesta: la impasibilidad. Nuestras sociedades se fundan de manera creciente en un conocimiento poderoso, vociferante y dogmático que también crece en impasibilidad, fragmentación y anestesia. Lo que Ilamamos desclasificación (GARCÍA GUTIÉRREZ, 2007; 2011a; 2011b; 2011c), consiste en un descomunal e íntimo trabajo cotidiano sobre la cultura, la identidad, la memoria o, en este caso particular, la organización del conocimiento, que propone la rehabilitación de esa dimensión estésica relegada por la maquinaria occidental de producción de sentido. Pero la propia savia del conocimiento se compone de pluralismo, de azar, de asimetría, de indeterminación, de histéresis (interrupciones en el proceso causal), de mestizaje e impureza. El orden y la organización no

\footnotetext{
${ }^{1}$ Así lo hace, por ejemplo, la Unión Europea en los indicadores manejados para establecer la calidad de los proyectos de investigación financiados sobre sociedad del conocimiento: rentabilidad, innovación tecnológica, comercialización, competitividad, serían algunos de ellos.(cfr. las recomendaciones a evaluadores de los Programas-Marco convocados por la Unión Europea, fundamentalmente del IV al VI PM)
} 
son opuestos al desorden, como suele pensarse, ni tampoco su complemento como pretende conciliar la complejidad (MORIN, 1996). No se trata de despejar el horizonte optando bien por el orden o por el desorden, como propician nuestros inflexibles principios lógicos sino, como veremos en el itinerario de paraconsistencia que nos hemos propuesto, inspirado en Newton da Costa $^{2}$, de concebirlos en un régimen de superposición y paradoja, quebrando la coherencia de las oposiciones.

El conocimiento se compone de conceptos (y los conceptos se componen de conocimiento), pero estos no constituyen células sólidas ni estancas por más que se empeñen cálculos, formalismos, definiciones y acotamientos. Los conceptos $^{3}$ son sedimentaciones efímeras y excepcionales del sentido, de larga trayectoria histórica, cognitiva y cultural, sobre los que una intencionalidad dada inflige un corte tomográfico que impide su flujo y fuga naturales. Tal corte se encarga fundamentalmente de una limpieza semiótica que evita vinculaciones a oscuros historiales de conceptos urdidos en inextricables genealogías. Habríamos de desarrollar, entonces, una especie de tafonomía ${ }^{4}$ simbólica aplicada al conocimiento -centrada en el estudio de sus desperdicios, desechos, entierros y destierros- para saber a partir de qué construcciones insaciables narramos y nos narra el mundo que nos rodea. De esta mirada arqueológica, que es también y a la vez una mirada proléptica, se ocupa la desclasificación como estrategia de producción de saberes y conceptos sensibles.

\section{La colonización del conocimiento}

La historia del mundo simbólico es la historia de los conceptos y de su colonización incesante. Por eso nos ha de interesar sobremanera la aproximación de los llamados "estudios poscoloniales" al ámbito de la organización de los saberes. Tal vez sea cierto, como afirman críticamente Hardt y Negri (HARDT; NEGRI, 2000), que la frescura inicial de los teóricos de la poscolonialidad se haya enredado en el manglar de unas viejas categorías coloniales de las que sus propuestas pretendían alertarnos y librarnos. La propia visión poscolonial del mundo llevaría implícita no sólo el inevitable lastre que tal prefijo suele arrastrar, en la razonable certidumbre de que podemos ocultar una deuda que no se saldará más que contrayendo otra sino, especialmente, la errónea sensación de acabamiento o superación que lo "pos-" sugiere.

\footnotetext{
${ }^{2}$ La paraconsistencia se consolida en los textos del matemático brasileño Newton da Costa (1997) analizada desde presupuestos lógicos: de una lógica que no pretende sustituir o rechazar la lógica convencional sino complementarla resolviendo situaciones en las que ésta muestra sus insuficiencias.

3 Vid el excelente trabajo de Francelin y Kobashi (2011) sobre una concepción más recortada del concepto/término, en el área de ciencia de la información. En este texto sin embargo tal concepción se basaría en la apertura ilimitada que observan Deleuze y Guattari (2001) en los conceptos que nos permite llevarlos a un productivo régimen contradictorio. Vid también las posibilidades de la desclasificación sobre una nueva visión de los conceptos en una organización plural de los conocimientos en Soares, Martin y Francelin (2013).

${ }^{4}$ La tafonomía es una parte de la paleontología que estudia los procesos que ocurren en los bioorganismos y desechos en enterramientos, basureros y otros yacimientos. Concretamente, la bioestratinomía se ocuparía de los procesos de descomposición, fragmentación o colonización de tales restos elaborando un discurso científico sobre ellos.
} 
A mi juicio, tanto el mundo biofísico, como el universo del conocimiento, son productos de recolonización incesante. Ningún organismo vivo consigue erradicar las bacterias porque si se despojara de unas, otras vendrían a colonizarlo $y$, si se desprendiera de todas, el organismo se habría transformado en pos-orgánico puesto que las propias bacterias son condición y síntoma de los biosistemas. Lo mismo ocurre con instancias inmateriales, como el conocimiento o el pensamiento, que no consiguen evitar la colonización o contaminación exterior, pues éstas forman parte de su inexorable evolución. Lo que importa, a la postre, es que una política colonial dominante del conocimiento, en el caso que nos ocupa, no termine por sustituir, y hasta erradicar, prácticas de saberes considerados periféricos o impida transgredir los límites epistemológicos de la propia producción de conocimiento. A esbozar algunas estrategias para la transgresión de tales límites dedicaré este trabajo.

El poder coloniza hacia fuera y hacia dentro. Desde Foucault (FOUCAULT, 1979) repensamos las relaciones humanas como construcción constante y fractalizada mediante prácticas de poder, en el trabajo, en la familia, en la pareja, un poder colonizante que no es parte de los sujetos sino, más bien, de la naturaleza microfísica de la propia relación social.

En ese sentido, lo poscolonial no existe como estado definitivo sino que acontece como proceso inestable e inexorable de recolonización de todas las instancias físicas y simbólicas. $\mathrm{Y}$, por tanto, los objetivos, las herramientas y nuestra propia posición perceptiva, enunciativa, ética y política -epistémica, en suma-, ante cualquier objeto de investigación, tendría que estar obligadamente atravesada por una voluntad descolonizadora y sensible que sólo reconoce el estado como cambio y la indomabilidad de su paradójico e inestable régimen.

La cultura, la identidad, la memoria, la racionalidad, la información o el conocimiento serían instancias colonizadas que difunden colonización. Las estructuras que, para Bataille o Althuser, siempre hablan por nuestra boca, fluyen particularmente en lo que conocemos y cómo conocemos, en lo que clasificamos y organizamos. He ahí uno de los desafíos teóricos fundamentales del pensamiento desclasificado: la producción de un conocimiento abierto, estésico, compasivo, escuchante, un conocimiento auto y heterodescolonizador que reconoce y regresa al sujeto.

Conocemos a través de conceptos que no están exentos, como las mencionadas bacterias, de ansias ignotas de colonización. Colonizamos al conocer, al enunciar y al organizar el conocimiento mediante conceptos ${ }^{5}$. Mediante conceptos cerrados, resemantizados y actualizados supuestamente narramos historias abiertas 0 remotas. Mediante conceptos rígidos predecimos futuros flexibles. Mediante conceptos estáticos describimos flujos y cambios. Son conceptos conocidos los que toman como rehén lo desconocido. De ahí que una conciencia descolonizadora, de la que no puede permitirse prescindir la teoría de la organización del conocimiento, habría de presidir cualquier movimiento

\footnotetext{
${ }^{5}$ Los conceptos se fraguan, ya lo decía Peirce, en la terceridad de la cultura (PEIRCE, 1975) pero, aun presos de ella, continúan siendo flujo y no fotograma (DELEUZE; GUATTARI, 2001).
} 
inevitablemente colonizador, especialmente si es involutivo. Ésta sería una primera paradoja que expresaré con la inigualable fuerza de un oxímoron: la desclasificación como proyecto de recolonización descolonizante.

El oxímoron manifiesta una contradicción al asociar conceptos opuestos -y en absoluto sería peyorativa la acusación de contradicción en el discurso desclasificado, como veremos- pero una contradicción, decía, que no sería circular sino perceptiblemente espiral, esto es, instituye un modo de pensar la descolonización del conocimiento utilizando otros instrumentos recolonizadores, reconoce la descolonización como un proceso inacabable, como la democracia, como la verdad para los falibilistas peirceanos, mas un proceso que avanza inexorablemente en pos de la utopía de la emancipación. La desclasificación superpone esa razón política a la razón tecnicista que suele dominar la organización del conocimiento.

Si pensamos desde un lugar fijo, objetos supuestamente fijos, estaremos organizando lo observado de acuerdo al orden convencional de la clasificación, esclerotizando el mundo desde una posición esclerotizada. La desclasificación propondría, sin embargo, una visión tan dinámica como incómoda ya que los objetos habrían de ser tan permanentemente sacudidos en su quietud como los sujetos que engañosamente los observan. El cambio que, para Heráclito y Hegel, a todo subyace sería, junto al propósito descolonizador, un elemento determinante de un escepticismo desclasificador que se fusiona, y he ahí un nuevo oxímoron, con la teoría crítica: un escepticismo crítico.

Por otro lado, surgen concepciones sobre la naturaleza de la realidad, ya sean constructivistas o representacionistas, cuya discusión no es considerada imprescindible por la desclasificación y la declara en punto muerto (en una analogía metafísica respecto al célebre séptimo aforismo de Wittgenstein (2002)). De hecho, para la desclasificación, la realidad sería una instancia progresivamente indecible desde el despertar de la conciencia de los homínidos, avanzando su indecibilidad conforme la mente conceptual y metaconceptual progresaba en describirla, nombrarla, clasificarla. El avance epistemológico implicó el destierro gradual de lo real y la expansión de nuestro mundo de lenguaje.

Sobre ese mundo, y no sobre la realidad (inefable), por tanto, heredamos y construimos conceptos que nos permiten observarlo y enunciarlo. Decidimos y juzgamos sobre observables, esto es, configuraciones conceptuales, representaciones de pretensión universal y totalista que sólo describen acciones o instancias situadas, desoladora y solitariamente situadas. La razón metonímica (SANTOS 2005; 2008), aquélla que racionalmente confunde la parte con el todo, y el género con la especie, nos hace creer que los observables y sus sistemas de descripción son totalidades que representan no ya nuestro propio mundo, sino el mundo de otras culturas y la realidad misma. Occidente tiene la peculiar convicción de que sus localismos han de ser de interés universal.

Los observables, y los sistemas conceptuales que los hacen posibles, surgen del logos, de una conciencia lógica especializada en la fabricación de conceptos y metaconceptos organizados por la racionalización, como 
dice Morin (1996), una enfermedad de la razón. Sobre esa euforia metonímica construye sigilosamente su poderosa "mito-lógica" el pensamiento dogmático.

Como producto de la cultura occidental, de un Occidente sin fronteras geográficas sino puramente epistémicas, surge la epistemología moderna imponiendo a las ciencias reglas estrictas que es incapaz de aplicarse a sí misma (SANTOS, 2005). La epistemología militariza la concepción pluralista del mundo. Los conceptos serían confinados en un cuartel, uniformados, ordenados y sometidos a una férrea e incuestionable jerarquía. Pero esos conceptos-soldados no sabrían nada de sus superiores, ni del mundo fuera del acuartelamiento, ni del sentido real del ejército más que del recibido mediante órdenes: el sentido de la jerarquía no es otro que el mantenimiento de su propia estructura. Los oficiales, por su parte, sólo percibirían cascos de acero, galones y uniformes, y nada sabrían del mundo de sus propios soldados, ni los reconocerían si fueran de paisano. El problema, como dicen Maturana y Varela (1999), es que no vemos que no vemos ¿Qué pensaríamos si alguien, desde tal ceguera, osara hacer informes completos del mundo exterior y de la realidad inalcanzable?, ¿qué podríamos esperar, no ya de la reducción practicada sino de tan disparatado empeño? Pues esas son, a nuestro juicio, algunas pretensiones de la epistemología.

\section{Consistencia y paraconsistencia conceptual}

Nuestro conocimiento se basa en una lógica de la consistencia. Pero la consistencia es una construcción incapaz de explicar todas las situaciones, incluso algunas situaciones cotidianas como, por ejemplo, el hecho de que vivir en tanto nos autoincineramos, de querer comer el pastel de chocolate pero, al mismo tiempo, no querer que se acabe o, de querer y no querer que nuestros hijos se hagan mayores. La constitución paraconsistente de nuestra mente se pone en evidencia en la "normalidad" de una racionalidad que fue capaz de Auschwitz ${ }^{6}$, o de la barbarie cotidiana a la que asiste una humanidad que ha perdido la capacidad de asombrarse y reaccionar. Sería necesario incursionar en las estructuras de la consistencia y cotejarlas con las estructuras de lo que empíricamente entendemos por prácticas de "normalidad". Los paradójicos resultados producirían perplejidad. Decimos paradójicos y, sin embargo, propondremos, al final de este trabajo, algunas configuraciones de la paraconsistencia como potente y modesto recurso desclasificador y transgresor de nuestros límites cognitivos.

La contradicción se agazapa en la microbiología del pensamiento y, por tanto, forma parte de la masa crítica del mundo que genera, de nuestro mundo. En ocasiones se arremolina dando sensación de límite infranqueable, de abismo, de descontrol, de pérdida. Es objeto de réplica inmediata y nos avergüenza si incurrimos en ella. Pero Kierkegaard dirá,

\footnotetext{
${ }^{6}$ Hecho que nos impondrá la necesidad de reinventar la filosofía, para Reyes Mate (MATE, 2008)
} 
no obstante, que "la paradoja es la pasión del pensamiento y el pensador sin paradoja es como el amante sin pasión: un mediocre modelo" ${ }^{\prime 7}$.

Las instancias del mundo se entrelazan como rizomas, con rupturas espontáneas, ausencias y alianzas inimaginables y azarosas, y es el logos lo que las convierte en armónicas, deterministas y autorreferenciales mediante un cierre de filas de los conceptos cuyos intersticios abismales y los flujos de sus porosidades son encubiertos por gramáticas, contextos y usos pragmáticos. Si decimos mil millones, cien millones 0 , incluso, cien personas, nuestra mente simula una imagen conceptual de la que habrá de zafarse inmediatamente para no quedar desbordada por una brevedad inacabable, por un laconismo ilimitado. Operamos con imágenes deliberadamente difusas, incluso para algo tan supuestamente concreto, pero tópicamente inabordable, como una cifra de dos dígitos.

No podemos tener ni siquiera una cartesiana idea, precisa, clara y distinta, del mundo abierto, entrelazado e inabarcable que representan diez kilómetros o una pequeña aldea. No somos capaces de aprehender simultánea o sintópicamente la totalidad de nuestra propia casa, del lugar donde trabajamos, de nuestra especialidad. Nos movemos lineal, precaria y discontínuamente por esos conceptos cerrados con pretensiones de totalidad, pero cuando asimos una leve parte se nos escapan todas las demás y la totalidad misma, que nunca sería igual a la suma de las partes, también totalidades, y ni siquiera a la totalidad que fue o podría llegar a ser en un instante o bajo otra óptica. ¿En qué indefensión estará el pensamiento, entonces, antes las abstracciones que constituyen, más allá de las concreciones, la mayor parte de nuestro imaginario conceptual?

Con sorprendente naturalidad nos aplicamos a utilizar conceptos que hablan de instancias posibles sólo porque osan invocarlas. Ni tan siquiera, amparado por estas objeciones, podemos adherirnos al viejo y confortable dilema nominalista. Para el nominalismo no existen los universales, la mujer, la humanidad, la esclavitud...sino entidades concretas: las mujeres, las personas, los esclavos, pero ¿qué son estas entidades ya contables sino instancias todavía inconcebibles ( $y$ esto sin pensar en el universo cuántico)? El problema de los universales no residiría en la idea imposible a la que nos lleva un concepto general sino en la imposibilidad de cualquier concepto concreto que pretenda clausurar el mundo que refiere. ¿Qué coincidencia habría entre dos interlocutores casuales con diferente experiencia sobre el concepto Rio de Janeiro?, ¿o sobre uno de sus distritos, calles o caserones, o la simple familia que vive en un modesto apartamento? ¿es posible asir en una sola palabra, o frase, o libro o biblioteca la complejidad de todos los atravesamientos históricos, magnitudes o asociaciones complejas que constituye Rio o cualquiera de sus componentes atómicos en el espacio o en el tiempo?, ¿qué mundo diverso y aprehensible representa el concepto de cariocas, o brasileños, o latinoamericanos, más allá de una cifra y unas cuantas pertenencias o

\footnotetext{
Quien rutinariamente va a trabajar por la mañana y a su casa por la tarde pensará que esto es una exageración, pero se pregunta el filósofo danés: "¿Cómo podría ocurrírsele que cae continuamente cuando camina derecho tras su nariz?" (KIERKEGAARD, 1997, p. 51).
} 
recuerdos desigualmente compartidos?, ¿eran brasileños los habitantes de Brasil hace 100, 500, 3000 años aun no guardando semejanza cultural con los brasileños de ahora?, ¿serán brasileños sus habitantes dentro de 10 siglos?, ¿cómo recoge una concepción cerrada la diversidad diacrónica y sincrónica de un lugar, su sociedad y las generaciones que lo habitaron?, ¿recogerá, un concepto, trayectorias y cambios?, ¿no son las trayectorias y cambios partes de la concepción del mundo?, ¿qué significado preciso tienen los conceptos de sociedad o generación, por ejemplo, en una trayectoria y cambio?, ¿es suficiente un fotograma, un concepto bidimensional, para expresar una fuga, una causa, una finalidad, un sentido, una duda, una contradicción, una apertura? Si no es suficiente ¿cómo es posible que salvemos tal laguna sémica y seamos capaces de cerrar y clasificar conceptos? La clasificación resuelve mediante trazo grueso y anestésico lo que, para el pensamiento desclasificado, resulta flujo imparable y vocación sensible. Las taxonomías que hacemos en realidad son inmateriales taxidermias.

El problema no reside, entonces, en la imposibilidad de los universales, como denunciaban los nominalistas, sino en la imposibilidad de los conceptos mismos como entidades cerradas sometidas por estructuras cerradas. La limitación -aunque tenemos muchas limitacionesno es mental sino epistemológica. El cerebro humano ha demostrado históricamente transgredir la concepción cerrada del mundo en las revoluciones, en la heurística, en el arte y hasta en la resolución pragmática de los dilemas cotidianos.

El mundo que percibimos está hecho de unos materiales a los que hemos dado nombre. Esos materiales no tienen jerarquía. Sólo los nombres o los conceptos se suceden y jerarquizan en la gran e incuestionable herencia conceptual que es la cultura. Los materiales que constituyen el mundo, y que nombramos, no están hechos de sí mismos sino de otros materiales a los que, en algún momento y escala de la composición, ya no podremos dar nombre pero no por ello dejan de determinar la naturaleza de los primeros más crucialmente, incluso, que los materiales accesibles o nombrados.

Los materiales innombrables o innombrados participan y son participados de los materiales nombrados. Pero pertenecen a otros mundos, muchas veces, a otras dimensiones. Un simio nunca podrá explicarse cómo fue el virus que lo extinguió. Un virus nunca tendría acceso al mundo del simio aunque es responsable de su muerte. Mas un virus también es ajeno a los materiales que le dan vida o le privan de ella. $Y$ esos materiales, pronto perderemos la noción de su biocondición, serán pasto de instancias ignotas que los acosan, condicionan y suspenden.

Todos y partes no dejan de ser simultáneamente partes y todos, causa y efectos no dejan de ser efectos y causas, como postula la complejidad, que fluyen en todas las dimensiones $y$ direcciones destruyendo y reconstruyendo sentido. Por ello, el escollo principal de los aparatos de la clasificación sería superado si lograra zafarse de toda pretensión de subordinar el sentido y comenzara a acompañarlo con 
incertidumbre y paraconsistencia. Pero, entonces, ya no sería clasificación lo que estaríamos practicando sino pensamiento desclasificado.

\section{La desclasificación y el discurso de las ciencias}

La desclasificación denuncia el dogmatismo epistemológico, el dogmatismo de convenciones y convicciones, que tan graves repercusiones causó en las relaciones interculturales y en la colonización automática y sistémica del otro. Cuenta el epistemólogo mexicano León Olivé (OLIVE, 1999) que, en Nueva Guinea Papúa, los ancianos de cierta etnia, al presentir una muerte inminente, solicitan a sus familiares ser sepultados en vida bajo el estiércol de sus animales, con el único auxilio de un canutillo que les permite respirar. En ocasiones, solidarios médicos convencidos de sus convenciones occidentales trataban de prolongarles la vida llevándolos a hospitales australianos impidiendo, así, su derecho a una muerte digna.

De este brutal episodio podemos extraer una analogía en nuestro campo de estudios: es ése el mismo tipo de violencia simbólica que nuestra clasificación del mundo, el modelo económico o la tecnología digital, aplican sobre muchos conocimientos con el mismo propósito de "salvarles la vida".

El mundo cotidiano está sobreclasificado, sobrerregulado, sobreconsensuado. El pensamiento único propicia también un sentido sin retorno. La desclasificación no niega la pulsión clasificadora ni se postula como solución universal. Lo que propone, ante la visión de un mundo diverso en vías de extinción, son instrumentos heterogéneos para repensar las prácticas organizativas en todos los dominios humanos. Rehabilita material procedente de los vertederos epistemológicos, recupera los productos del mestizaje y de la promiscuidad interconceptual desechados por la epistemología dominante, reciclando la contradicción como un recurso paraepistemológico que permite otra visiones del mundo, - la restauración de la retórica, a partir de Perelman (1989), no como mero atrezzo dialéctico sino como condición constructiva del conocimiento mismo. La desclasificación llama a la incorrección política mediante la desobediencia simbólica y epistemológica como única posibilidad que tienen la creatividad, la emancipación y el disenso y, por lo tanto, un futuro descolonizado para los conocimientos. Sólo a través de la autoprovocación, dirá Peter Sloterdijk (2002, p. 99), surgen posibilidades de no seguir desmoralizándose.

La desclasificación ignora sistemáticamente fronteras y barreras y practica un pensamiento fronterizo desde un sur epistémico (en el sentido disperso y diverso, aunque convergente, de Walter Mignolo, Gloria Anzaldúa, Abdelkhebir Khatibi ${ }^{8}$, Boaventura Santos, Enrique Dussel o Franco Cassano $^{9}$ ). Reconoce que la contradicción atraviesa todas las

\footnotetext{
${ }^{8}$ Vid el desarrollo estratégico de conceptos como paradigma-otro (desarrollado por Mignolo), pensamiento-otro (Khatibi), lenguaje-otro y new mestiza (Anzaldúa) en Mignolo (2003).

9 Vid en la misma línea, de los anteriores, los trabajos sobre pensamiento fronterizo y pensamiento del sur (SANTOS, 2005; 2008), transmodernidad (Dussel, 1994) o pensamiento meridiano (CASSANO, 2004).
} 
instancias y situaciones $y$, con especial ahínco, anida en los espacios interconceptuales, inbetween ${ }^{10}$, desarbolando la propia concepción de nuestros conceptos y evitando distingos entre conocimiento científico o vulgar, entre otras cosas, porque no reconoce jurisdicción alguna, ni dicotomía alguna, aun no librándose de ellas más que mediante un esforzado ejercicio metacognitivo. La ciencia no sería, para la desclasificación, un lugar privilegiado de enunciación aunque sí un lugar que se autoprivilegia. Un lugar que no necesita ser desmontado porque en su propia dialéctica se autodesmonta hacia un supuesto, y utópico, conocimiento absoluto. La ciencia no produce todo el conocimiento, produce conocimiento científico, un tipo de conocimiento sujeto a rigurosas restricciones y cierres en sus métodos de construcción y a una frívola ceguera respecto a la porosidad de su aparato conceptual. Miles de culturas, a lo largo de la historia, han producido conocimiento eficiente en las selvas, lagos y desiertos, en ausencia de epistemología. De ahí que la desclasificación no se declare contra-epistemológica, pues reconoce los productos de la epistemología, sino pos o paraepistemológica adheriéndose a una hermenéutica sensible, militante, crítica. En la estela del pensamiento poscolonial, la desclasificación no pretende proponer otro modo más de conocer, sino en la estela terminológica de los teóricos poscoloniales citados, un "modo-otro" de hacerlo, un "conocimiento-otro" (MIGNOLO, 2003).

Aunque determinados avances de la ciencia han ayudado a mitigar el ancestral sufrimiento humano, muchas veces ignorando la promoción colateral de sufrimiento humano de nuevo cuño, la ciencia -como cualquier otro proceso dialéctico, no sólo en diacronía sino también en sincronía- ha tenido sus luces y sombras paraconsistentes. El problema del discurso de la ciencia, a ojos de la desclasificación, es triple:

1- su pretensión de autoerigirse como discurso privilegiado en relación a la producción de conocimiento relevante sin plantearse la pregunta ineludible: ¿un conocimiento para qué y para quién? En muchas ocasiones, gnoseologías "primitivas" o "periféricas", generalmente advertidas como ignorantes a pesar de su condición mayoritaria, han sabido proveer auxilio y felicidad a millones de personas y generaciones humildes, discriminadas, durante milenios.

2- su osadía de autoproclamar la obtención de la verdad ignorando la más leve objeción falibilista (cfr. el pragmatismo peirceano). $\mathrm{Si}$, en el pasado, la verdad provenía de la palabra revelada, en el presente y en el futuro los científicos serán los patrocinadores de una Revelación antes reservada a dioses y profetas. Ahora, es la ciencia la que nos promete, y retrasa, el acceso al paraíso.

3- la negación de toda fe o creencia, a la vez que los científicos tienen fe y "creen" en su propio discurso y en la

\footnotetext{
${ }^{10}$ El concepto es de Homi Bhabha y ha sido traducido al español por "entridad" o lo "entre".
} 
argumentación científica cuando, en efecto, toda argumentación destinada a convencer viene regida por la retórica (Santos, 2005). A esta alturas, la complejidad de los universos parece suficientemente evidente como para no confiar en la fortaleza de ningún discurso. La fe en un único discurso no hace sino relegarnos al conocimiento que proporciona una sola matriz cognitiva -es como la vulnerable economía del monocultivo-, reduciendo los márgenes de maniobra de la propia heurística, y opacando multitud de opciones y "radicales-libres" de la imaginación.

el rechazo de la irracionalidad, la pulsión o la retórica, cuando la propia racionalidad es ambivalente y tanto se pone al servicio y justificación de pulsiones como la codicia, la dominación 0 el miedo como reprime la libertad y la diversidad, como hicieran La Inquisición o el Apartheid, o apoya justamente a sus contrarias. Racionalizar desde el miedo -un miedo estratégico- es, para la mayoría, no sólo garantía de supervivencia social, sino también un sutil modo de superación de lo temido, una paradójica rampa de lanzamiento del instinto dominador. Por otra parte, el caso de Ulises, ante las sirenas, ilustra cómo poner la razón como obstáculo al impulso. Sería, este pasaje ${ }^{11}$, un eficaz aliado de muchas morales religiosas que, en boca de algunos geniales portavoces, como Cervantes, con automática crueldad devolvió la cordura a un Don Quijote moribundo, para hacerlo testigo de su propia agonía ${ }^{12}$. Si el episodio de Ulises coloca la razón al servicio de la voluntad, el de Don Quijote la sitúa al servicio de la fe dogmática.

La ciencia occidental no libera ni reinventa la cognición porque, ella misma, es prisionera de sus procesos de inferencia, de sus propios protocolos, atavismos, liturgias y sociología, de sus nomenclaturas y clasificaciones. La desclasificación, entonces, no habrá de ocultar su predilección por la hermenéutica antes que por la epistemología o por una gnoseología mestiza que, como la del arte, no abandone ni desprecie cualquier itinerario de la creación.

\section{La producción dicotómica de conocimiento}

A continuación, apuntaremos varias limitaciones evidentes de nuestro modo tradicional de conocer, organizar, transmitir y producir conocimiento, que tanto promueve excluyentes y reductoras dicotomías como estigmatiza las paradojas naturales. La lógica dicotómica, para comenzar, fue inoculada en las culturas por la racionalidad moral más antigua: la que estableciera la estructura conceptual entre el bien y el mal, entre lo bueno y lo malo. Spinoza, sin embargo, quebrando tan

\footnotetext{
${ }^{11}$ Analizado desde su teoría de la racionalidad imperfecta por Elster (1989).

${ }^{12}$ De tan dramático automatismo se percata Nietszche en su Genealogía de la moral (1997)
} 
perversa tradición, llegaría a decir en su Ética que no deseamos las cosas buenas sino que las cosas son buenas, justamente, porque las deseamos.

Un automatismo cognitivo, no obstante, riega nuestra cognición, hasta el punto de que no sólo debo afirmar la dimensión dicotómica de todo discurso, sino que habremos de reconocer que nuestro propio discurso metacognitivo sobre las dicotomías podría difícilmente librarse de ellas. En ese sentido, no hay más salida que instalarse en la reflexividad, observarse observando, pensarse pensando y en una enunciación autocrítica. Las dicotomías producen conocimiento, no cabe duda, pero un conocimiento reductor e incapaz de abandonar una doble y férrea vía.

El mundo nos ha sido legado en conceptos clasificados estructuralmente respecto a supuestos contrarios. La naturaleza de tal modo de concepción se basa en las siguientes propiedades:

1- binarismo: la subjetividad manifiesta, vive y percibe el mundo en pares conceptuales: bueno o malo, fiel o infiel, hombre o mujer, norte o sur. La comprensión, la automatización y la sumisión simbólicas se favorecen enormemente al reducirse las alternativas a una polarización binaria;

2- oposición: esos pares no necesariamente armónicos o amistosos, se ofrecen como expresión de una tensión o conflicto, legitimándolo: bueno versus malo, fiel versus infiel, hombre versus mujer, norte versus sur;

3- subordinación: el orden del par no sería neutral sino determinado por el criterio del pensamiento hegemónico: el bien sobre el mal, el fiel sobre el infiel, el hombre sobre la mujer, el norte sobre el sur;

4- generalización y exclusión negativa: en ciertas dicotomías el elemento subordinado se presenta peyorativamente como negación de la instancia subordinante con la que se abre el par, a través de prefijos como in-(fiel), des(leal), no(ortodoxo), a-(normal), etc., representando habitualmente la instancia negada un mundo mayor o más diverso que el que representa la instancia negadora: cristianos/infieles (musulmanes, animistas, budistas, ateos, agnósticos...), normal/anormal e, incluso, epistemología/hermenéutica, por más que la hermenéutica acepta la epistemología como un modo más de interpretación, pero no al contrario, o con clasificado/desclasificado ante el mismo argumento.

Veamos algunos valiosos modos de superación dicotómica, propuestos por algunos autores, junto a varias propuestas de la desclasificación:

- Boaventura Santos (2005) anima, por ejemplo, a estudiar el elemento final, y habitualmente más discriminado en las dicotomías, 
disociándolo del cepo de la oposición: el universo de la mujer sin el hombre, de los colonizados sin los colonizadores, del sur sin el norte, de los negros sin los blancos. Este ejercicio emancipador no sólo habría de ser conceptual sino, eminentemente, político y práctico. Sin embargo, una extirpación radical de los opuestos nos llevaría a otros modos reductores de la enunciación y percepción del mundo. Aun siendo útil la propuesta, un "pensar sin" puede no mejorar el "pensar contra". Mucho más enriquecedor resulta su hermenéutica diatópica, que consiste en pensar y traducir interculturalmente a partir de tópoi o premisas argumentales para construir un lugar común o reconocible de comunicación mutua (labor que Santos emprende buscando diálogo entre los Derechos humanos occidentales, la Umma islámica y la Dharma hindú);

- Morin, por su parte, ensaya un método de inteligibilidad que no logra desprenderse satisfactoriamente de las categorías del pensamiento que denuncia. Para la complejidad, los contrarios no serían, en realidad, opuestos, sino más bien complementarios: el desorden forma parte del orden y viceversa, la luz de la oscuridad, como si fueran la cara y cruz de una moneda, ya, metafóricamente desgastada. Aun considerando el notorio avance cognitivo que produce la conciliación de los opuestos, esa nueva y armónica conceptualización no iría mucho más allá de los deseos de salvación de una pareja que ya no funciona o que nunca debió existir.

- la desclasificación habría de superar, desde la convicción de incompletud, tanto la cooperación de contrarios que propone Morin como el solipsismo conceptual en el que, en ciertos casos, podría caer la propuesta de Santos. Veamos un fascinante ejemplo cinematográfico, que citamos con frecuencia, para clarificar y justificar la necesidad de algunas elementales herramientas desclasificadoras: en el excelente, duro y poético film $X X Y$, de la argentina Lucía Puenzo (2007), su protagonista Alex -un/a adolescente de quince años, clasificado/a como intersexual o hermafrodita por las taxonomías médicas - es interpelado/a por su padre (un sobrio Ricardo Darín) quien, con amable naturalidad, quería averiguar qué sexo elegiría el/la niño/a cuando se sometiera a cirugía, masculino o femenino: ¿y si no hubiera nada que elegir? le respondería, eligiendo, Alex.

En este ejemplo, no se trata de elaborar una cooperación necesaria de lo masculino con lo femenino o de pensar feminidad o masculinidad de modo independiente, sino de abordarlos simultáneamente: como manifiesta Alex, en este caso, "no hay nada que elegir". La misma racionalidad dicotómica no sólo excluye la opción de "no jugar" sino que desconsidera los intersticios y gamas de grises entre blanco/negro, masculino/femenino, sí/no ó 1/0 (infinitos números). Esta lógica binarista, $1 / 0$, abierto/cerrado, sería la misma que subyace tras la fundamentación de la tecnología digital, junto al álgebra boolena de los motores de búsqueda y complejos algoritmos de Google, Yahoo o Bing que, más allá de la binarización, gatillan direccionamientos simbólicos, comerciales, ideológicos.

Sin agotar las posibilidades de nuestro abierto "juego de lenguaje", la desclasificación propone detectar y desmantelar las dicotomías como 
formulación epistemológica privilegiada, en el propio discurso bien antes que en el ajeno o, en todo caso, utilizarlas como un modo no privilegiado, y a veces poco oportuno, reductor y autocomplaciente, de obtención de conocimiento. En la desclasificación habríamos de quebrar las dicotomías automáticas, llevarlas al límite de su régimen paradójico hasta la extenuación de la lógica mutilante que trasladan. Deconstruirlas, si es preciso, mediante otras dicotomías, a condición de avanzar de la lógica dicotómica hacia el pluralismo lógico. Pero la desclasificación no pretende abolir el pensamiento dicotómico sino abolirlo como pensamiento dominante. De hecho, desde la desclasificación podrían elaborarse dicotomías calculadas para producir, en sus propios límites paradójicos, conocimiento imprevisible. Por ejemplo, como presentamos en un trabajo anterior (2007), mediante la construcción de oxímora a partir del desmantelamiento de dicotomías: de la oposición tradicional centro/periferia resultaría, por un lado, el oxímoron /centro periférico/ (el Bronx en Nueva York) y, por otro, el oxímoron hiperbático /periferia central/ (Leblón en Rio de Janeiro)

\section{Postulados, conclusiones y aperturas de investigació}

Veamos, para provisionalmente concluir, tres postulados teóricos de la desclasificación como modo de conocimiento-otro transgrediendo límites y recuperando una contradicción calculada como recurso (pos)epistemológico:

1. toda instancia tiene un régimen abierto y puede ser, a la vez, otra y múltiple, más allá de las posibilidades de las polijerarquías. Infinidad de entrelazamientos nocionales acechan a las instancias configurando y reconfigurando las proposiciones en un eje sintagmático que devora la verticalidad paradigmática. Ninguna propiedad es esencial para una concepto ni ha de ser privilegiada sobre las demás. Concretamente, William James advertirá: "no existe ninguna propiedad absolutamente esencial a ninguna cosa... La esencia de una cosa es aquélla de sus propiedades que es tan importante para mi interés que, en comparación con ella, puedo ignorar todas las demás"13.

Cuando aludimos, con automatismo o inocencia, a las partes, clases, propiedades o funciones de una casa o de un coche, de una institución, de una ciudad, de un ordenador, de los ciudadanos, estamos clasificando el mundo esencialistamente. El verbo ser, explícita o tácitamente, conexiona la parte con su todo, la clase con su especie: la rueda (es) del coche, la pantalla (es) del ordenador, la cocina (es) de la casa, la casa es una vivienda, las sardinas son peces, el ordenador es tecnología, Juan es abogado... Estas operaciones esencialistas consisten en organizar (se) el mundo a partir de una lógica unicista y reductora, pues afirma negando u

\footnotetext{
${ }^{13}$ La traducción es mía. El texto original reza: "there is no property absolutely essential to any one thing ... The essence of a thing is that one of its properties which is so important for my interests that in comparison with it I may neglect the rest" (James, 1927, II: 333, 335 apud Dousa, 2009:4) Se trata del mismo James que invocará una rebelión contra los propios principios éticos cuando estos se vuelven un obstáculo (vid. GARCÍA GUTIÉRREZ, 2007).
} 
ocultando los mundos posibles que invoca la lógica modal y, sobre todo, los mundos de hecho. Esa lógica práctica es un recurso de la clasificación convencional.

La fórmula desclasificada será, por tanto: una instancia no sólo es, es también. Llamaremos, a este primer aserto, estrategia de extensión ontológica o identitaria. Al extender los límites de la esencia, esta estrategia los borra, despurifica, hibrida, contamina imaginarias esencias, abre y devalúa las jerarquías. Su objetivo es la impugnación del principio sagrado de identidad: A=A y la sumisión conceptual a lo supraconceptual. He aquí varios argumentos desclasificados: " $A$ " nunca es igual a sí misma ya que la lógica del cambio impide un estado. La representación de " $A$ " sería igual a sí misma fuera del tiempo pero, fuera de la temporalidad, no hay concepción de " $A$ ", ni concepción alguna. " $A$ " sería una representación de algo exterior a " $A$ ", que no es " $A$ ". La jerarquía es una ordenación convencional entre los conceptos $\mathrm{y}$, por tanto, responde a un orden epistemológico dado que no es "natural" y tampoco interculturalmente compartido.

2. Abordemos, ahora, una segunda formulación, decurrente de la anterior: si una instancia no sólo es, sino que siempre es también, entonces posiblemente también no sea en otros mundos posibles y, en al menos uno de ellos, necesariamente no sería. Las posibilidades de no-ser fluyen entre las posibilidades de ser, y subrayo bien el plural: posibilidades de no-ser. Sabemos que existen numerosas manifestaciones de ser, introducidas por "es también", tal vez tantas posibilidades como situaciones enunciativas $y$, sin embargo, no por desconocer el dominio del no-ser, podemos reconocerle al no-ser tan sólo una posibilidad absoluta: simplemente "no-ser". El no-ser es producto de la insuficiencia o del reduccionismo perceptivo de la conciencia esencialista y, por tanto, seguramente tan voluble, elástico, reversible como el ser y con muchas otras propiedades inefables, que no pueden ser dichas, 0 dichas todavía. $Y$ esto, sin perjucio de que el mundo negado (por el noser) podría ser mucho más complejo que el mundo afirmado (por el ser).

Deduzcamos descondicionando y dejando ímplicito el liberador modo contrafáctico ${ }^{14}$, del argumento "si una instancia no sólo es, sino que es también, entonces posiblemente también podría no ser", la siguiente fórmula: una instancia que es también, también no es. Llamaremos, a este segundo aserto, estrategia de contradicción necesaria. El objetivo de esta estrategia es objetar y forzar la conculcación, hasta la última resistencia epistémica contraria, del principio logicista de no contradicción. Veámosla sobre los ejemplos anteriores: el centro es periferia y la periferia es centro, el norte es sur y el sur es norte, lo bello es feo y lo feo es bello, los fieles son infieles y los infieles son fieles...

3. Por último, llamaremos a un tercer modo desclasificador de superación dicotómica, estrategia de superposición disolutiva, y actúa sobre los casos que permiten una visión simultánea de los dos polos de la

${ }^{14}$ Esto es, la enunciación privilegiada por la lógica modal de D. Lewis por ejemplo (si fuera, si lloviera, habría, sería...). 
dicotomía: "Ser o no ser" ya no es la cuestión, la cuestión sería "ser y no ser". Una instancia es o no es, principio del tercero excluido, introduce una brecha metonímica en las bases del pensamiento. Proponer -y forzarque una instancia pudiera ser y no ser sintópica y sincrónicamente, en multitud de ocasiones, la repara.

Seríamos, entonces, simultáneamente racionales e irracionales (sin oponer o concebir complementariamente tales instancias), juzgadores y juzgados, educadores y educandos, depredadores y depredados (por más que la especialización profesional positivista se empeñe en lo contrario, la riada del sentido todo lo inunda). Seríamos todavía mucho más, aplicando nuevamente el oxímoron hiperbático (inverso) a las formulaciones 1 y 2 : observadores observados y no sólo observados observadores, dominadores dominados y no sólo dominados dominadores. Esta circunstancia no afectaría exclusivamente a roles humanos sino también a cualidades físicas o a cualquier otra instancia o propiedad podría ser susceptible de paraconsistencia: guapos y feos, altos y bajos, generosos y egoístas. La superficie es profunda y la profundidad superficial: los abisales están exactamente donde han de estar ¿a qué profundidad inversa estaría una barco para ellos? El norte siempre es sur y todo occidente es también oriente. En el planeta, en el espacio exterior, y especialmente en el mundo cuántico, subir, bajar, estar o no estar, son tan sólo cuestión de narración, de enunciadores y enunciatarios. Las bifurcaciones y sesgos son producto de perspectivas y situaciones. Una instancia no tiene más valor que el que le concede su "instante", ni más sentido que el que le otorga una perspectiva inamovible $y$, por tanto, dogmática, cerrada, imposible ( $y$ contradictoria) en sí misma.

En cuanto a la jerarquía, arquitectura lógica (y política) de la clasificación convencional del mundo, la desclasificación rompería con su base opositiva todo/parte y especie/género al considerarlas como una variedad de dicotomía asimétrica. Y lo mismo ocurre con el sometimiento de los adjetivos y propiedades a los sustantivos y a otros supuestos cimientos cognitivos. En la cognición desclasificada, todas las esencias serían canjeables y solubles, todos los conceptos precarios y negociables.

Un automóvil rojo no sólo sería "esencialmente" automóvil sino también, "esencialmente" rojo. El sustantivo habría de perder sus privilegios milenarios sobre la cualidad: el automóvil rojo es un buen representante del genérico vehículo pero también de la rojedad y de muchas propiedades y extensiones implícitas en la noción automóvil rojo: de las partes, componentes y funciones de todo automóvil y también de la genealogía que le ha llevado a ser lo que es y de lo que representa: ejemplo de modernidad, de desarrollo, de polución, etc.. Tal vez sólo nos fijemos en un automóvil por la intensidad de su color, porque es metálico o porque se mueve a gran velocidad, lo que devalúa el estatuto del propio automóvil. Habitualmente, el sustantivo ha ocupado una centralidad que opaca el pensamiento adjetivo, periférico. De ahí que sea una prioridad de la desclasificación rehabilitar todo ese aparataje "secundario" del lenguaje y amnistiar a los presos del logicismo. 
El motor o la rueda no estarían subordinados al todo automóvil ni éste a la presencia de tales partes aunque, sin ellas, no habría movimiento autónomo aunque, curiosamente, todavía sí automóvil. Mas se trata de colaboración, no de jerarquía. La jerarquía sólo es de orden epistémico y el orden epistémico depende de un ejercicio de poder enunciativo. Además, ninguna supuesta parte es exclusiva de un todo, ni existe un todo que no sea parte, ni de algún modo desbordable o desmontable por arriba, por abajo, transversal o temporalmente desde todas esas imaginarias escalas. Tampoco podemos cerrar el inventario de escalas, ni de ópticas, ni limitar una escala convencional que necesariamente se perdería en confines subatómicos o galácticos. Y esto no sólo ocurre con lo que podríamos reducir a la conceptualización de objetos y a los objetos en sí mismos -si estuvieran dotados de una inmunidad imposible a otras configuraciones- sino exactamente igual en lo que concierne a las representaciones de ideas consideradas abstractas. La distinción entre lo abstracto y lo concreto es una falsa distinción porque el mundo que elaboramos epistemológicamente tal vez contenga la misma asombrosa proporción de conceptualidad "oscura" que la materia.

Y un último e imprescindible apunte que sitúa estas preocupaciones en nuestra época: las tecnologías de la comunicación que durante milenios fueron producto de la diversidad de las culturas territoriales, de las geoculturas, por primera vez en la historia están siendo colonizadas por una tecnología hegemónica, la digital, desde donde se dictan los nuevos patrones simbólicos de una nueva cultura global, descatalogada e inclasificable, que prefiero llamar transcultura (GARCÍA GUTIÉRREZ, 2011b). La transcultura es el propio intercambio acelerado e incesante de valores, categorías y universos simbólicos cada vez más desarraigados de sus matrices culturales originarias que supone la quiebra de cosmovisiones verticales y de tradiciones, ya en disolución. Destituye las viejas clasificaciones jerárquicas y las mitologías del mundo, impregnadas en el lenguaje que las crea y mantiene, pero instaura una férrea estructura horizontal unificante que somete igualmente a los sujetos. La transcultura extingue valores y prácticas ancestrales, unos de incalculable valor para la diversidad y otros fundados desde la infamia, pero también debe verse como un nuevo espacio que permita repensar, abolir o revertir conceptos, ordenaciones, fronteras, hegemonías, dependencias, esencialismos, anestesias ${ }^{15}$.

Ante su lógica arrasadora, ya no serían suficientes las estrategias interculturales, y $\mathrm{ni}$ siquiera las operaciones transmodernas y poscoloniales si no están acompañadas del salto neoepistémico y paralógico que promueve una racionalidad que ha de ser insobornablemente desclasificante, descolonizante y sensible. Para cumplir con tales objetivos, y aunque suene ingrato, la desclasificación sería utilizada, entonces, como la célebre escalera de Wittgenstein (2002), a la

\footnotetext{
${ }^{15}$ En mi trabajo (GARCÍA GUTIÉRREZ, 2011b) se descifran las claves de la transcultura y se contempla la posibilidad de un pensamiento desclasificado y emancipador cuyas líneas maestras, aplicadas a la organización del conocimiento, se esbozan aquí.
} 
que habríamos de dar una patada una vez subidos al muro de nuestra inagotable industria conceptual.

A una determinada vanguardia de la Organización del Conocimiento, desprovista de complejos, oportunismos y miedos, le corresponde abordar la (des)clasificación de los saberes con el objetivo que tomamos de Holloway (2002): cambiar el mundo sin tomar el poder.

\section{Bibliografía}

BAUDRILLARD, J. El intercambio imposible. Madrid: Cátedra, 2000.

CASSANO, F. Pensamiento meridiano. Buenos Aires: Losada, 2004.

CASTELLS, M. Comunicación y poder. Madrid: Alianza, 2010.

COSTA, N. C. A. da. O conhecimento cientifico. São Paulo: Discurso, 1997.

DELEUZE, G.; GUATTARI, F. ¿Qué es la filosofía? Barcelona: Anagrama, 2001.

DOUSA, T. M. Classical pragmatism and its varieties: on a pluriform metatheoretical perspective for knowledge organization. In: Proceedings of NORTH AMERICAN SYMPOSIUM ON KNOWLEDGE ORGANIZATION, 2, 2009. p. 1-9.

DUSSEL, E. 1492: El encubrimiento del otro. Hacia el origen del mito de la modernidad. La Paz: Plural ediciones, 1994.

ELSTER, J. Ulises y las sirenas: estudios sobre racionalidad e irracionalidad. México: FCE. 1989.

FOUCAULT, M. Microfísica del poder. Madrid: Las ediciones de la Piqueta, 1979.

FRANCELIN, M. M.; KOBASHI, N. Y. Concepções sobre o conceito na organização da informação e do conhecimento. Ciência da Informação, v. 40, n. 2, maio/ago., p. 207-228, 2011.

GARCÍA GUTIÉRREZ, A. Desclasificados: pluralismo lógico y violencia de la clasificación. Barcelona: Anthropos, 2007.

GARCÍA GUTIÉRREZ, A. Outra memória é possível: estratégias descolonizadoras do arquivo mundial. Petrópolis: Vozes, 2008.

GARCÍA GUTIÉRREZ, A. Declassification in knowledge organization: a post-epistemological essay. Transinformaçao, v. 23, n. 1, p. 5-14, 2011 a.

GARCÍA GUTIÉRREZ, A. Pensar en la transcultura. Madrid: Plaza y Valdés, 2011b.

GARCÍA GUTIÉRREZ, A. Epistemología de la documentación. Barcelona: Stonberg, 2011C.

HARDT, M.; NEGRI, A. Imperio. Barcelona: Paidós, 2002.

HOLLOWAY, J. Cambiar el mundo sin tomar el poder. Barcelona: Viejo Topo, 2002. 
JAMES, W. Pragmatismo: un nuevo nombre para viejas formas de pensar. Madrid: Alianza Editorial, 2007.

KIERKEGAARD, S. Migajas filosóficas o un poco de filosofía. Madrid: Trotta, 1997.

MATE, R. La razón de los vencidos. Barcelona: Anthropos, 2008.

MATURANA, H.; VARELA, F. El árbol del conocimiento: las bases biológicas de conocimiento humano. Madrid: Debate, 1999.

MIGNOLO, W. Historias locales, diseños globales: colonialidad, conocimiento subalterno y pensamiento fronterizo. Madrid: Akal, 2003.

MORIN, E. Introducción al pensamiento complejo. Barcelona: Gedisa, 1996.

NIETZSCHE, F. La genealogía de la moral. Madrid: Alianza Editorial, 1997. OLIVÉ, L. Multiculturalismo y pluralismo. México: Paidós, 1999.

PEIRCE, C. S. Semiótica e filosofia (textos escolhidos de Peirce). São Paulo: Cultrix, 1975.

PERELMAN, Ch.; OLBRECHTS-TYTECA, L. Tratado de la argumentación: la nueva retórica. Madrid: Gredos, 1989.

SANTOS, B. de S. El milenio huérfano. Madrid: Trotta, 2005.

SANTOS, B. de S. A filosofia à venda, a douta ignorância e a aposta de Pascal. Revista Crítica de Ciências Sociais, v. 80, p. 11-43, mar. 2008.

SLOTERDIJK, P. El desprecio de las masas. Valencia: Pre-textos, 2002.

SOARES, M. S.; MARTIN, M. T.; FRANCELIN, M. M. Pluralismo lógico e epistemografia interativa como ferramentas desclassificadoras do conhecimento. Revista digital de Biblioteconomia e Ciência da Informaçao, v. 11, n. 1, p. 55-71, jan./abr. 2013.

SODRÉ, M. Antropológica do espelho. Petrópolis: Vozes, 2002.

WITTGENSTEIN, L. Tractatus logico-philosophicus. Madrid: Tecnos, 2002. 